\title{
Global Wind Speed and Wave Height Extremes Derived from Long-Duration Satellite Records
}

\author{
Alicia TAKBASH AND IAN R. YOUNG \\ Department of Infrastructure Engineering, University of Melbourne, Parkville, Victoria, Australia \\ ØYVIND BREIVIK \\ Norwegian Meteorological Institute, and University of Bergen, Bergen, Norway
}

(Manuscript received 14 August 2018, in final form 11 October 2018)

\begin{abstract}
The application of extreme-value analysis to long-duration (30 year) global altimeter and radiometer datasets is considered. In contrast to previous extreme-value analyses of satellite data, the dataset is sufficiently long to enable a peaks over threshold analysis to be undertaken. When applied to altimeter data for wind speed and significant wave height, this analysis produces values consistent with buoy validation data and previous numerical model reanalysis datasets. The spatial distributions produced are also consistent with the model reanalysis data. However, the altimeter data shows much greater finescale structure for wind speed, which is consistent with known tropical cyclone activity. The greater data density provided by radiometer measurements offers the potential to address altimeter undersampling. However, issues associated with the radiometer's inability to measure wind speed in heavy rain events appears to create an unacceptable "fair weather" bias at extreme wind speeds. This renders the radiometer data of wind speed largely unusable for the investigation of wind speed extremes. The study also clearly demonstrates the limitations of the initial distribution method for extreme-value analysis, which is heavily biased by mean conditions.
\end{abstract}

\section{Introduction}

The determination of extreme-value estimates of environmental parameters such as wind speed and wave height is a common requirement for many coastal and offshore applications. In the present context, "extreme value" is used to describe the statistical estimate of the wind speed or wave height, which, for instance, may be expected to be exceeded once in, say, 100 years. That is, the 100 -yr return period wind speed or wave height. Alternatively, it can be described as the wind speed or wave height that has a probability of occurrence of 0.01 in any year.

The typical approach for the estimation of such extreme-value parameters is to analyze a long-duration time series of measured wind speed or wave height. As the record is almost always shorter than the desired return period, the procedure used is to fit a chosen form for the probability distribution function (PDF)

Corresponding author: Ian R. Young, ian.young@unimelb.edu. au of the recorded data and then extrapolate to the desired probability level (e.g., 0.01 for a $100-y r$ return level).

A number of practical challenges arise in this form of analysis. As the focus is on the extreme-value "tail" of the PDF, how well this part of the PDF is defined and how well the, often arbitrary, analytical form for the PDF fits the data is critical. Obviously, it is desirable to reduce the extent of the required extrapolation of the PDF as much as possible. As a result, there is a strong requirement to have as long of a measured time series as possible at the location or locations of interest.

The most obvious approach to obtain long-duration measured records is to use buoy or fixed offshore platform data. Although suitable long-duration records exist at specific sites, the key shortcoming of such data is that it has very limited spatial distribution and hence is seldom at the location required. One approach to overcome both the temporal duration and spatial distribution issues is to use numerical model data. Indeed, longduration reanalyses of wind speed and wave height, 
which include data assimilation from satellites, are available [e.g., ERA-40 (Uppala et al. 2005) and ERA-Interim (Dee et al. 2011)]. Naturally, these datasets are only as good as the models used to produce them. Although present-day atmospheric circulation and surface wave models are remarkably reliable, their performance under extreme conditions is still limited.

The advent of Earth-observing satellites has provided a long (approximately 30 year) record of global wind speed and wave height, and a number of previous studies (Alves and Young 2003; Young et al. 2012) have examined the suitability of such data for extreme-value analysis (EVA). Although these studies have shown potential, they highlight a number of issues with such data. These issues include the following: as data invariably come from multiple satellites, careful long-term calibrations are required; the datasets considered were not sufficiently long to apply statistically sound approaches to extrapolation of the PDF; there were questions about the extreme-value performance of such satellite systems; and the spatial separation of satellite ground tracks means that radar altimeters may undersample extremes.

The present study examines a long-term (almost 30 year) calibrated and validated dataset of wind speed and wave height obtained from both altimeter and radiometer systems. As will be shown, the duration of the record is now such that the peaks over threshold (PoT) method can be used for EVA of the data. The resulting global distributions are consistent with the limited point measurements of extreme wind speeds and wave heights from buoys, as well as with numerical reanalyses. In addition, for the first time, global distributions clearly show dominant storm tracks and tropical cyclone activity. As radiometer systems simultaneously measure a broad swath of the ocean, they have the potential to significantly enhance the quantity of data available and hence address issues of perceived undersampling. However, limitations in the performance of radiometer data when applied to EVA will also be highlighted.

The arrangement of the paper is as follows. Section 2 provides a brief review of previous studies of global extreme-value estimates and the statistical approaches adopted. This is followed in section 3 by a description of the satellite dataset used in the present analysis and its calibration, particularly under extreme conditions. Section 4 compares extreme-value estimates from the present satellite measurements with buoy observations. A discussion of global distributions of extreme-value wind speed and wave height using a variety of statistical techniques and both satellite data types (altimeter and radiometer) is provided in section 5. Finally, discussion of the results and conclusions are provided in section 6 .

\section{Global estimates of extreme wind speed and wave height}

\section{a. Extreme-value theory}

As outlined by Goda (1988) and Coles (2001), the aim of EVA is to estimate the probability distribution of the extreme values of a variable from a record of empirical samples. To achieve valid estimates of the extremes, the data should be independent and identically distributed (IID). For the present applications, the requirement of independence means that successive observed data points should be statistically uncorrelated. As a result, there should not be multiple data points associated with the same storm. As typical storms may have durations of many hours, this means that successive data points may need to be separated by up to $48 \mathrm{~h}$ to ensure independence (Lopatoukhin et al. 2000; Caires and Sterl 2005; Vinoth and Young 2011). The requirement to be identically distributed is satisfied when data points in a sample show a common parent distribution in a population. Should an area be subjected to quite different meteorological phenomena (e.g., trade winds and tropical cyclones), it is likely that these systems will have quite different PDFs and the data should be partitioned and each PDF considered separately (Vinoth and Young 2011). It should be noted that as the present dataset does not provide a mechanism to separate independent storm climate systems, no attempt has been made to partition the data.

There are three general approaches to EVA that have been used in wind/wave applications-the initial distribution method (IDM; Goda 1988, 1992; Ochi 1992; Tucker 1991; Lopatoukhin et al. 2000; Vinoth and Young 2011), the annual maximum method (AMM; Coles 2001), and the PoT (Goda 1992; Ferreira and Soares 1998; Van Gelder and Vrijling 1999; Alves and Young 2003; Vinoth and Young 2011).

\section{1) IDM}

The most obvious means of forming the PDF is to simply create a histogram of recorded wind/wave data. Such data, when obtained from in situ instruments, is typically measured at hourly (or 3 hourly) intervals. A parametric PDF can then be selected, fitted to the data, and extrapolated to the desired probability level $P\left(x<x^{100}\right)$, where $x$ can be either wind speed $U_{10}$ or significant wave height $H_{s}$. For the present application $P\left(x<x^{100}\right)$ represents the probability level associated with the 100 -yr event (i.e., probability of exceedance of 0.01 in any year). For the IDM approach (Tucker 1991; Cooper and Forristall 1997; Teng 1998), $P\left(x<x^{100}\right)$ is given by

$$
P\left(x<x^{100}\right)=1-D / T_{100}
$$


where $D$ is a decorrelation time scale in hours for observations of $x$, and $T_{100}$ is the number of hours in 100 years. There is little theoretical guidance on the choice of the value for $D$. Studies using buoy data (Tucker 1991; Cooper and Forristall 1997; Teng 1998) have usually adopted $D=3$ hours, although it is almost certain that actual decorrelation scales for ocean waves are considerably longer. Rather, it seems that $D$ might better be described as a calibration term. The empirical nature of the IDM extends beyond the choice of $D$. There is also no theoretical guidance in terms of the PDF that should be used to fit the data. Gumbel and Weibull distributions are often used, the ultimate choice being the form that best fits the observed PDF. The Gumbel distribution is defined as

$$
F(x)=\exp \left[-\exp \left(-\frac{x-A}{B}\right)\right]
$$

where $F(x)$ is the cumulative distribution function; the Weibull distribution takes the form

$$
F(x)=1-\exp \left[-\left(\frac{x-A}{B}\right)^{k}\right]
$$

and $k, A$, and $B$ are shape, location, and scale parameters, respectively.

There are still further limitations with the IDM approach. First, in most cases, the approach violates the requirement for independent and identically distributed data. When using in situ data measured at 1- or 3-h intervals, it is almost certain that such data are correlated. As the distribution is fitted to the full PDF, it is highly likely that data at the peak of the PDF (mean conditions) and that in the extreme tail (storms) will be from different meteorological events and hence not identically distributed. Finally, the fit of the chosen PDF to the data is always dominated by the bulk of the data, which is near the peak of the PDF, rather than the extreme tails where interest lies. Hence, the IDM tends to be an extrapolation of these more benign conditions than a model of the extremes. Despite these very significant shortcomings, the IDM has been extensively used (Goda 1992, 1988; Tucker 1991; Ochi 1992), as it is the only alternative when only short time series are available (i.e., less than 15 years). In the case of Earthobserving satellites, the observational record has been so short that previous attempts at EVA have only yielded reasonable results when the IDM has been used (Alves and Young 2003; Chen et al. 2004; Challenor et al. 2005; Wimmer et al. 2006; Vinoth and Young 2011).

\section{2) $\mathrm{AMM}$}

One method to overcome the many limitations of the IDM approach is to use so-called block maxima. In this approach, the maximum value from a meteorologically appropriate period is considered, rather than all the data. The period might be a season or, more commonly, a year (the annual maximum). In such a case, it can be shown that these maxima will follow a generalized extreme-value (GEV) distribution (Castillo 1988; Coles 2001):

$$
F(x)=\exp \left\{-\left[1+k\left(\frac{x-A}{B}\right)\right]^{-1 / k}\right\} .
$$

Depending on the value of the shape parameter $k$ the GEV takes on three forms:

Type 1 or Gumbel distribution $k=0$, (unbounded) Type 2 or Fréchet distribution $k>0$, (unbounded)

Type 3 or Weibull distribution $k<0$, (bounded)

For $k \geq 0$, there is no upper bound to the distribution, and values of $x$ can take on infinitely large values, although at very low probability levels. In contrast, for $k<0$ there is an upper bound to the magnitude of $x$. In addition, it should be noted that (4) is a distribution of maxima, whereas (3) is actually a distribution of minima (although used for maxima by considering the distribution of negative values $-x$ ). Although the AMM has the advantage of a sound theoretical basis and ensures that the data are IID, it has the very significant limitation of requiring very long time series (greater than 30 years) to form stable estimates of the PDF (i.e., only one value per year). In practice, such long time series are seldom available for the case of wind/ wave data.

\section{3) PoT}

A compromise that addresses the data availability limitation of the AMM is the PoT approach (Castillo 1988; Coles 2001). Here, a threshold is set and only exceedences above this threshold considered. In such a case, it can be shown that data will follow a generalized Pareto distribution (GPD; Coles 2001),

$$
F(x)=1-\left[1+k\left(\frac{x-A}{B}\right)^{-1 / k}\right],
$$

where $A$ becomes the value of the threshold. In this approach, there is no theoretical guidance in the selection of the threshold parameter $A$ and it is usually a trade-off between stability and bias. That is, it must be low enough to ensure sufficient data are available to fit a 
stable PDF, while not so low that it biases the fit to the extreme values in the distribution. It is common to select a value at a chosen high percentile (e.g., 90th or 95th percentile; Anderson et al. 2001; Caires and Sterl 2005; Challenor et al. 2005, Alves and Young 2003; Vinoth and Young 2011). It should be noted, however, that the selection of the threshold does affect the extreme-value estimates. In addition, the values chosen above the threshold must still be independent (e.g., from separate storms). This is often achieved by ensuring data are separated by some defined time period (e.g., $48 \mathrm{~h}$; Lopatoukhin et al. 2000; Caires and Sterl 2005).

In the case of the PoT approach, the desired probability level for a 100 -yr return period is

$$
P\left(x<x^{100}\right)=1-N_{Y} /\left(100 N_{\mathrm{PoT}}\right),
$$

where $N_{\text {PoT }}$ is the number of data points in the PoT analysis, and $N_{Y}$ is the number of years covered by the analysis.

\section{b. Previous global extreme-value studies}

The literature on extreme-value studies of wind speed and wave height is extensive. The vast majority of these studies, however, refer to point locations. We have not attempted to review this literature here, rather we concentrate on the more limited global studies. As a result, attention is confined to either numerical reanalysis model or satellite datasets.

A number of long-duration reanalyses combining numerical models of the atmosphere with data assimilation are now available in public archives. These include ERA-40 (Uppala et al. 2005) and ERA-Interim (Dee et al. 2011), for both of which a wave model (WAM; Hasselmann et al. 1988) is incorporated into the model system. Because of the long duration of the reanalyses, these are attractive for EVA (e.g., Caires and Sterl 2005; Sterl and Caires 2005). The length of the reanalysis model records allows the use of threshold methods (PoT) to determine global distributions of the 100 -yr return period wind speed $U_{10}^{100}$ and significant wave height $H_{s}^{100}$. Such datasets have three significant limitations: the spatial resolution means that intense small-scale events such as tropical cyclones are not well resolved, the ability of the models to reliably model extreme events has been questioned (Stopa and Cheung 2014), and the quantity of data assimilated into the models varies with time, meaning that reanalysis data may not be temporally stationary (Breivik et al. 2014; Aarnes et al. 2012, 2015). It should be pointed out that the issue of model resolution is being continually improved as computational capabilities improve. The ERA-5 reanalysis, which is presently being developed, will reduce spatial resolution to $30 \mathrm{~km}$ (https://www.ecmwf.int/en/ forecasts/datasets/archive-datasets/reanalysis-datasets/ era5).

An innovative alternative to the use of reanalysis data is to create very long-duration equivalent time series using forecast ensembles (Breivik et al. 2013, 2014; Meucci et al. 2018). By considering ensemble forecasts at long forecast lead times (9-10 days), synthetic datasets of durations longer than 300 years can be formed. With such data, EVA can be performed without the need of any assumed PDF form (the probability level is "in sample" and can be determined directly from the ranked data). This effectively removes issues of extrapolation to the desired probability level, but questions about stationarity and tail biases (the ability of a coarse model to represent extreme events) remain.

As the satellite records lengthened, a number of studies investigated global values of extreme wind speed and wave height. These include Alves and Young (2003; 10 years of data), Chen et al. (2004; 8 years of data), Challenor et al. (2005; 11 years of data), Wimmer et al. (2006; 11 years of data), and Vinoth and Young (2011; 23 years of data). Vinoth and Young (2011) investigated the use of PoT analyses but concluded that the time series was too short and hence adopted an IDM analysis, as did all the previous studies. Although these analyses produce plausible global distributions of $U_{10}^{100}$ and $H_{s}^{100}$ and comparable values to point buoy measurements, there are again doubts about whether the instruments accurately measure extreme conditions and, perhaps more importantly, whether they undersample extreme events due to the satellite orbit and footprint size (i.e., storm peaks or whole storms may be missed as altimeter ground tracks can be separated by hundreds of kilometers). It should be noted that all of these studies use radar altimeters with very narrow swaths on Earth's surface. Instruments such as radiometers and scatterometers, which measure over a broad swath, have not previously been used for global extreme-value analysis.

\section{Satellite dataset}

In the present study, we will use the calibrated and validated satellite database of Young et al. (2017). This database consists of altimeter $\left(H_{s}\right.$ and $\left.U_{10}\right)$ and radiometer $\left(U_{10}\right)$ data over the period 1984-2014 (30 years). The data come from a total of 23 different satellites over this period. Each of these satellite datasets was individually calibrated (i.e., linear regression correction-slope and offset) against NDBC buoy data, validated against an independent buoy dataset, and cross validated at crossover points with other satellite systems. In addition, the satellites were examined for any discontinuities or drifts 
in calibration over time, and where these were detected, the data were corrected.

A full description of the manner in which altimeters measure wind speed and wave height and radiometers measure wind speed can be found in Young et al. (2017) and Young and Donelan (2018). These details are not repeated here. However, there are a number of issues that are important when such data are subjected to EVA. Altimeters are "nadir looking" instruments and measure along a line directly below the satellite. The footprint is approximately $8-10 \mathrm{~km}$ in diameter with roughly one measurement per second. As a result, altimeters have very good along-track resolution (approximately every $10 \mathrm{~km}$ ) but relatively low across-track measurement density. Depending on the orbit, ground tracks are $100-400 \mathrm{~km}$ apart at the equator. The exact repeat cycle or time until the satellite repeats the same ground track varies from 3 to 10 days. As a result, altimeters in polar orbits observe the globe from about $80^{\circ} \mathrm{S}$ to $80^{\circ} \mathrm{N}$ but may undersample or completely miss small- to medium-size storms. Although there have been very few studies on the impact of rain on altimeter measurements, it appears that they are not greatly affected by rain (Young and Donelan 2018).

In contrast, radiometers (which measure only wind speed), measure over a broad swath, approximately $1400 \mathrm{~km}$ wide. Across this swath, they provide data at approximately $25 \mathrm{~km}$ resolution. Therefore, a typical radiometer in a polar orbit will visit most points on Earth's surface twice per day. At a particular location, the radiometer will typically produce approximately 30 times more data than an altimeter. Hence, radiometers should be much less affected by undersampling than altimeters. However, radiometer measurements are heavily influenced by rain and typically cannot measure under heavy rain conditions. As a result, it is very common for radiometers to miss the peaks of storms where there is commonly heavy rain. As a result, this may introduce a "fair weather" bias in radiometer data (Young et al. 2017; Young and Donelan 2018).

In addition to calibrating the instruments, Young et al. (2017) also examined their performance at extreme conditions. This was accomplished by examining quantilequantile (QQ) plots between altimeter/radiometer and buoy data, as well as QQ plots between altimeter and radiometer winds at crossover points. They concluded that compared to buoys, altimeters measure $H_{s}$ accurately up to $10 \mathrm{~m}$ and $U_{10}$ to $25 \mathrm{~m} \mathrm{~s}^{-1}$. This was as high as reliable matchup data were available, and it is likely that this good performance extends beyond these values. It should be noted that the choice of algorithm relating radar cross section to wind speed for altimeters is critical to their high-wind performance. Young et al. (2017) used a

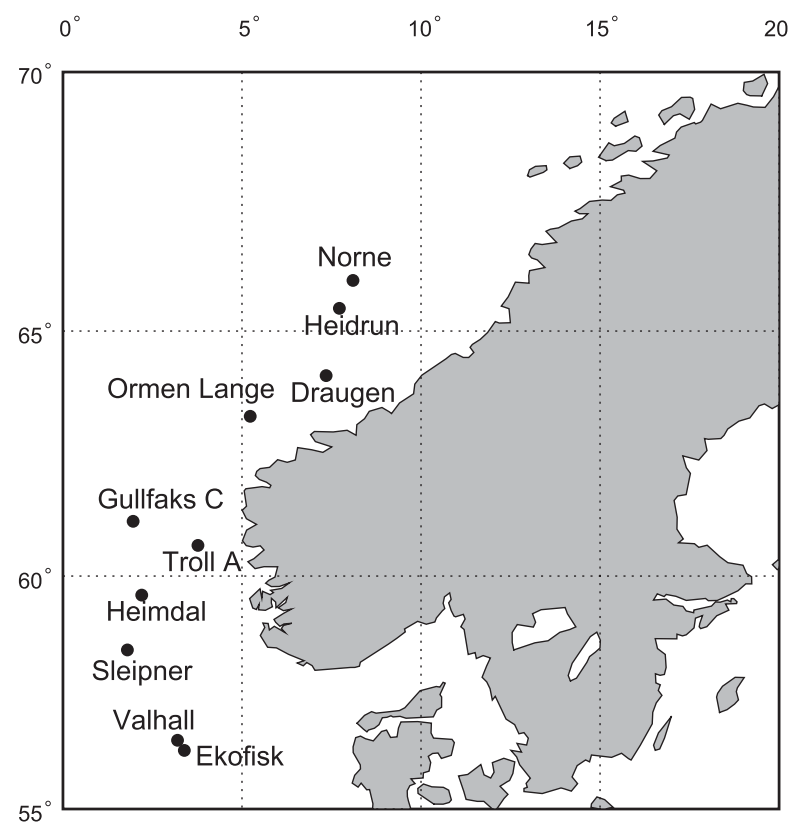

FIG. 1. Locations of offshore platforms used to obtain anemometer data for high wind speed calibration of the radiometer instruments.

combination of the form proposed by Abdalla (2007) with the high wind speed correction of Young (1993). This same combination has been used here.

In contrast to altimeters, radiometers appeared to overestimate wind speed compared to buoys above $20 \mathrm{~m} \mathrm{~s}^{-1}$. However, there is evidence (Large et al. 1995; Zeng and Brown 1998; Taylor and Yelland 2001; Howden et al. 2008; Bender et al. 2010; Jensen et al. 2015) that buoys may underestimate extreme wind speeds and waves due to tilting of the buoy and sheltering by large waves. It is therefore questionable to assume that buoys represent "ground truth" under extreme conditions.

As high-wind performance is critical for EVA, we therefore searched for alternative wind observations to conventional buoys. The obvious alternative is offshore platform data. Data were obtained from the Norwegian Meteorological Institute for offshore oil platforms. The locations where data were available are shown in Fig. 1. Offshore platform data are known to have a number of issues, most notably flow distortion caused by the structure. However, this dataset has been extensively studied by the Norwegian oil industry, and power-law corrections were available for each of the anemometers to correct the data to a standard reference height of $10 \mathrm{~m}$. The same matchup criteria adopted by Young et al. (2017) were used. That is, the satellite data needed to be within $50 \mathrm{~km}$ of the platform, and the mismatch in measurement time must be less than $30 \mathrm{~min}$. One of 

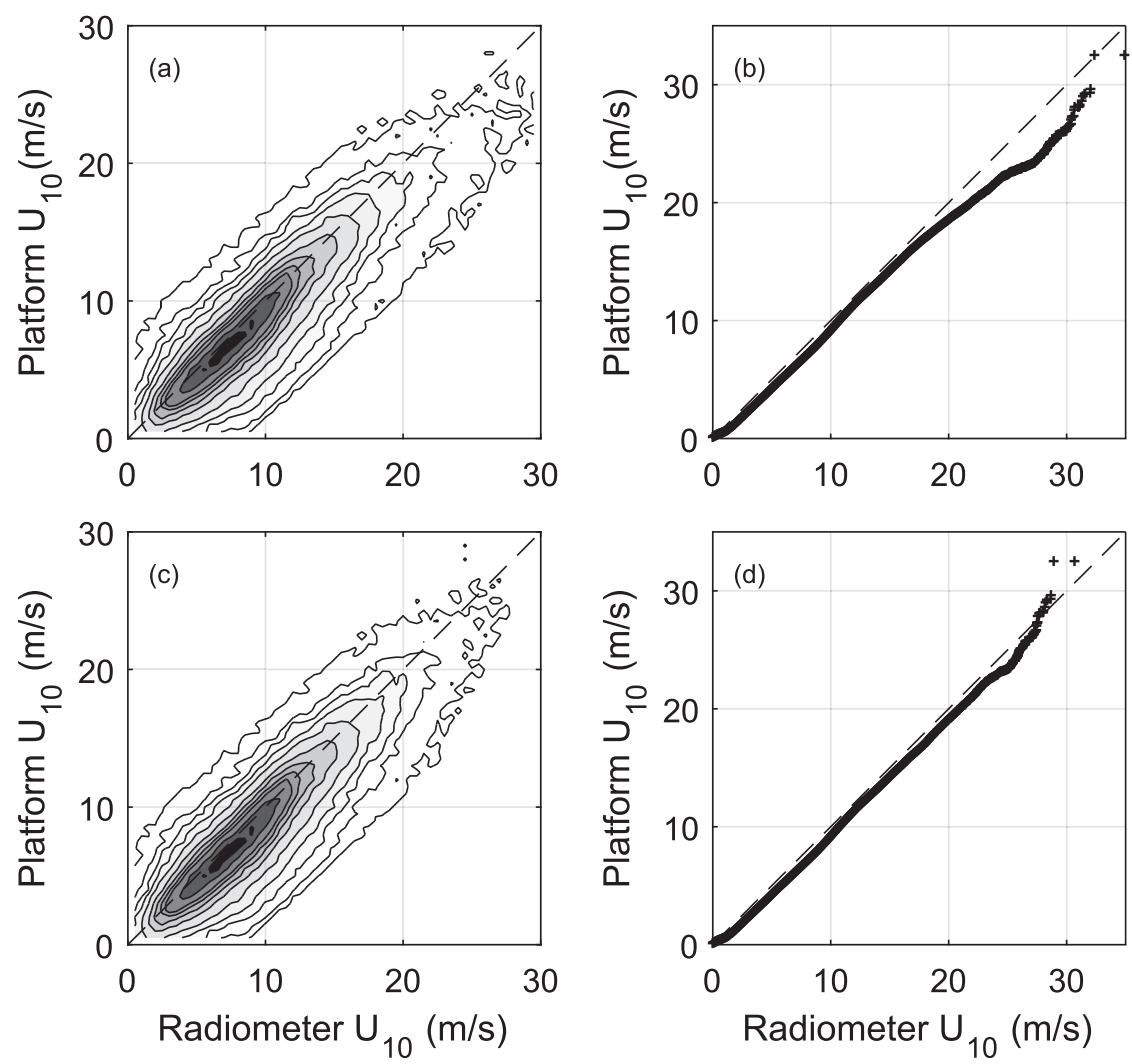

FIG. 2. Radiometer-platform anemometer comparisons: (left) scatterplots and (right) QQ plots with (a),(b) no high wind speed correction and (c),(d) high wind speed correction [(7)].

the challenges in carrying out a high wind speed calibration is obtaining sufficient data under these conditions (i.e., there are few collocated observations at high winds).

To maximize the available data, only radiometer passes were considered (30 times more data than for the altimeter). In addition, as the results of Young et al. (2017) showed that there was little calibration difference between the various radiometers, these were all pooled to form a single composite dataset. The dataset consisted of more than 280000 matchups, but only $1 \%$ of the wind measurements exceeded $20 \mathrm{~m} \mathrm{~s}^{-1}$. Figure 2 shows both scatterplots of platform and radiometer winds and the corresponding QQ plots. Figure 2a shows the relationship between radiometer wind speed with the Young et al. (2017) calibration applied and the platform anemometer winds. Below $20 \mathrm{~m} \mathrm{~s}^{-1}$, the data agree remarkably well, indicating that the boundary layer corrections applied to the platform data were valid and there was minimal impact from flow distortion around the platforms. Above approximately $20 \mathrm{~m} \mathrm{~s}^{-1}$, however, a gradual rolloff in the data is apparent (radiometer winds are higher than platform winds). This is more clearly seen in the corresponding QQ plot
(Fig. 2b). To address this issue, the following empirical correction was applied to data above $18 \mathrm{~m} \mathrm{~s}^{-1}$ :

$$
U_{10}^{*}=U_{10}\left[1-0.013\left(U_{10}-18\right)^{0.79}\right],
$$

where $U_{10}$ is the radiometer wind speed, after the calibration relations of Young et al. (2017) are applied, and $U_{10}^{*}$ is the corrected wind speed. In (7), units for wind speed are meters per second. Figures $2 \mathrm{c}$ and $2 \mathrm{~d}$ show the results once the correction in (7) has been applied. It should be noted that (7) is based entirely on the data from the Norwegian sites shown in Fig. 1. It has been assumed that this calibration holds generally and has subsequently been applied globally.

\section{Validation of satellite EVA analysis against buoys}

Following Alves and Young (2003) and Vinoth and Young (2011), the global data were binned into $2^{\circ} \times 2^{\circ}$ bins. In section 5 , this binned dataset is used to investigate global distributions of extreme values. Here, we validate the results against NDBC buoy data (Evans et al. 2003). We select the same 10 deep-water NDBC 

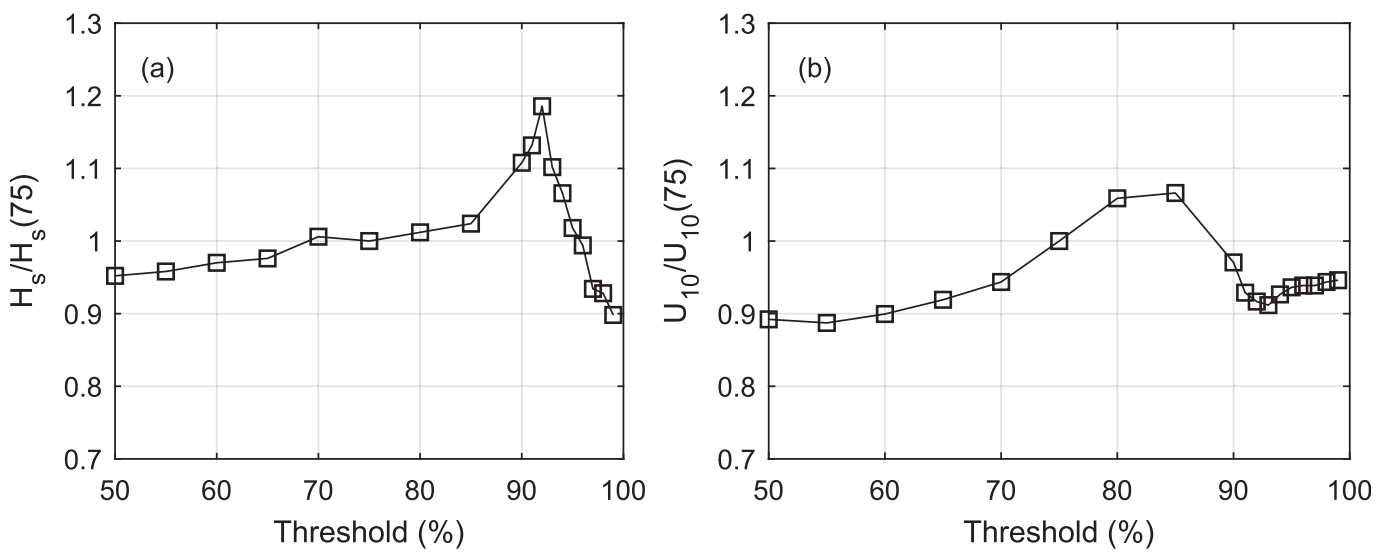

FIG. 3. Values of (a) $H_{s}^{100}$ and (b) $U_{10}^{100}$ as a function of the threshold used for the PoT analysis, expressed as a percentile. Values are shown normalized by the value at the 75 th percentile. Data taken from a representative $2^{\circ} \times 2^{\circ}$ region centered on $40^{\circ} \mathrm{N}, 180^{\circ} \mathrm{E}$ (North Pacific).

buoys used by Vinoth and Young (2011; see their Fig. 2). These buoys were selected, as they are all more than $200 \mathrm{~km}$ from shore, have a water depth exceeding $300 \mathrm{~m}$, and were operational for the full duration of the combined satellite datasets (1984-2014).

The validation approach used by Vinoth and Young (2011) consisted of determining extreme-value estimates $\left(U_{10}^{100}, H_{s}^{100}\right)$ using both IDM and PoT approaches for both buoy and satellite (altimeter in their case). They then compared IDM estimates for buoy with altimeter and PoT estimates for buoy with altimeter (i.e., they compared IDM buoy with IDM altimeter and PoT buoy with PoT altimeter). What this showed was that the IDM results agreed well, but the PoT approach exhibited significant differences. This is not surprising as the IDM fit is actually dominated by the body of the distribution rather than the tail. As long as buoys and altimeters produced similar mean conditions, the IDM approach will give extremes of comparable magnitude.

As we have longer time series, we have adopted a more challenging validation approach. With 30 years of data, PoT estimates from buoys can be obtained with reasonable confidence. Therefore, we take the PoT estimates from the buoys as the baseline (ground truth) and compare satellite estimates from PoT and IDM with these values. An important issue in applying the PoT analysis is to select an appropriate threshold parameter [ $A$ in (5)]. To investigate the sensitivity of extreme-value estimates from the GPD [(5)] to the threshold value, a $2^{\circ} \times 2^{\circ}$ region centered on $40^{\circ} \mathrm{N}, 180^{\circ}$ (North Pacific) was selected as a representative test point. The values of $U_{10}^{100}$ and $H_{s}^{100}$ were calculated using the PoT approach and the altimeter data for a number of different values of threshold, each specified as a percentile value. The results, normalized by the value with a threshold at the 75th percentile are shown in Fig. 3. For both wind speed and wave height, the extreme-value estimates increase as the threshold value is increased before reaching a peak and then decreasing. Depending on the threshold choice, the resulting extreme values can vary by up to $30 \%$. The values of $H_{s}^{100}$ are more sensitive to the choice of threshold than $U_{10}^{100}$. Ultimately, the 90th percentile was adopted for the subsequent calculations. This choice was largely dictated by a desire to avoid the region of Fig. 3 where the values seem most sensitive to the choice, while keeping the threshold value as high as possible. Other locations were also tested and, although there are differences, Fig. 3 is broadly representative.

When applying a PoT analysis to the satellite data, care must still be exercised to ensure that the data taken above the selected threshold are independent. In the case of altimeter passes, this is seldom an issue as, even with multiple satellites in orbit, satellite passes at a location are typically separated by at least two days ( $48 \mathrm{~h})$. Radiometer data are potentially more problematic, as a single radiometer will image each location twice a day (12-h separation). To test the sensitivity to these issues, data were filtered such that only values separated by chosen times were considered (e.g., data separated by $48 \mathrm{~h}$ ). The calculated extreme values were quite insensitive to the chosen time separation, and, hence, data separated by a minimum of $48 \mathrm{~h}$ have been used here.

Table 1 shows values of $U_{10}^{100}$ and $H_{s}^{100}$ for buoys calculated using the PoT approach (values shown in italics columns of the table). These are compared to altimeter values calculated with both PoT and IDM $\left(U_{10}, H_{s}\right)$ and radiometer values calculated with $\operatorname{IDM}\left(U_{10}\right)$. As will be outlined in detail in section 5, the radiometer data proved unsuitable for application of the PoT approach and hence 
TABLE 1. EVA of NDBC buoy and satellite data. Buoy data shown with italics.

\begin{tabular}{|c|c|c|c|c|c|c|c|c|}
\hline Buoy No. & $\begin{array}{l}\text { Lat }\left({ }^{\circ} \mathrm{N}\right) \text {, } \\
\text { lon }\left({ }^{\circ} \mathrm{E}\right)\end{array}$ & $\begin{array}{c}H_{s} \text { buoy } \\
(\mathrm{PoT})(\mathrm{m})\end{array}$ & $\begin{array}{l}H_{s} \text { altimeter } \\
(\mathrm{PoT})(\mathrm{m})\end{array}$ & $\begin{array}{l}H_{s} \text { altimeter } \\
(\mathrm{IDM})(\mathrm{m})\end{array}$ & $\begin{array}{c}U_{10} \text { buoy } \\
\left(\text { PoT) }\left(\mathrm{m} \mathrm{s}^{-1}\right)\right.\end{array}$ & $\begin{array}{l}U_{10} \text { altimeter } \\
(\mathrm{PoT})\left(\mathrm{m} \mathrm{s}^{-1}\right)\end{array}$ & $\begin{array}{c}U_{10} \text { altimeter } \\
(\mathrm{IDM})\left(\mathrm{m} \mathrm{s}^{-1}\right)\end{array}$ & $\begin{array}{l}U_{10} \text { radiometer } \\
(\mathrm{IDM})\left(\mathrm{m} \mathrm{s}^{-1}\right)\end{array}$ \\
\hline 46001 & $56.23,212.05$ & 13.8 & 12.7 & 14.5 & 24.9 & 28.9 & 33.9 & 34.2 \\
\hline 46002 & $42.61,229.46$ & 14.7 & 13.1 & 12.7 & 24.4 & 26.3 & 30.4 & 29.9 \\
\hline 46003 & $51.33,204.15$ & 16.1 & 14.8 & 15.7 & 26.1 & 29.2 & 34.8 & 29.2 \\
\hline 46005 & $46.14,228.93$ & 14.6 & 14.4 & 14.6 & 25.3 & 27.9 & 31.1 & 30.9 \\
\hline 46006 & $40.78,222.60$ & 15.4 & 13.4 & 14.8 & 27.2 & 27.5 & 27.5 & 31.2 \\
\hline 51005 & $24.42,197.90$ & 11.9 & 10.4 & 9.9 & 18.9 & 26.7 & 25.8 & 26.9 \\
\hline 44004 & $38.48,289.57$ & 13.5 & 13.8 & 13.6 & 27.3 & 34.4 & 37.0 & 34.4 \\
\hline 41002 & $31.76,285.16$ & 13.5 & 11.6 & 10.4 & 25.9 & 33.2 & 33.2 & 30.4 \\
\hline 42001 & $25.90,270.33$ & 11.5 & 11.3 & 11.3 & 28.1 & 26.4 & 26.4 & 26.2 \\
\hline 42002 & $26.09,266.24$ & 11.5 & 10.8 & 7.1 & 26.3 & 31.0 & 26.0 & 27.2 \\
\hline Error & - & - & $-7.5 \%$ & $-8.7 \%$ & - & $+14.6 \%$ & $+20.3 \%$ & $+18.1 \%$ \\
\hline
\end{tabular}

is not considered here. The values of $U_{10}^{100}$ and $H_{s}^{100}$ calculated for buoys using the PoT are in good agreement with those of Vinoth and Young (2011). The differences can be attributed to the longer duration of measurements used here and a different threshold for the PoT analysis. To determine the differences between buoys and satellites, the mean error was calculated as

$$
\Delta r=\left(H_{s, \text { Alt }}^{100}-H_{s, \text { Buoy }}^{100}\right) / H_{s, \text { Buoy }}^{100},
$$

for each buoy and then summed over all $n$ buoys as $r=1 / n \sum \Delta r$. The mean error was calculated for $U_{10}^{100}$ in a similar fashion. The altimeter PoT values are in reasonable agreement with the buoys with $r=-7.5 \%$ for $H_{s}^{100}$ and $r=+14.6 \%$ for $U_{10}^{100}$. These values compare to Vinoth and Young (2011), who obtained $r=-17.31 \%$ for $H_{s}^{100}$ and $r=+40.61 \%$ for $U_{10}^{100}$. Vinoth and Young (2011) ultimately concluded that the PoT approach could not be applied to determine extreme values using their dataset. The results in Table 1 seem to indicate that, at least at these buoy locations, the altimeter yields extreme-value estimates in reasonable agreement with buoys using the PoT approach.

As noted earlier, we have not presented IDM estimates for buoys. An examination of the results of Vinoth and Young (2011) shows that $H_{s}^{100}$ for the buoys are in reasonable agreement between PoT and IDM analyses using $D=3 \mathrm{~h}$. However, $U_{10}^{100}$ buoy calculations with IDM were between $30 \%$ and $50 \%$ larger than the corresponding PoT calculations. This is perhaps not surprising, as the value of $3 \mathrm{~h}$ was developed for use with buoy data of $H_{s}$. When applied to $U_{10}$, and other data, this value of $D$ is questionable. This raises very significant doubts about the use of the IDM approach. To obtain values of $U_{10}^{100}$ and $H_{s}^{100}$ with satellite data that were comparable to satellite or buoy PoT calculations, the values of $D$ needed to be significantly increased.
To obtain values of comparable magnitude for use in comparative plots in section 5, these values were arbitrarily increased to $D=500 \mathrm{~h}$ for wind speed (both altimeter and radiometer) and $D=30 \mathrm{~h}$ for significant wave height (altimeter). For completeness, calculations in Table 1 for IDM have also used these values. As will be shown in section 5, we do not advocate the use of the IDM, and the arbitrary nature of the selection of $D$ is just one of its limitations.

\section{Global distribution of extremes}

\section{a. Altimeter PoT analysis}

To investigate the global distribution of $U_{10}^{100}$ and $H_{s}^{100}$, the data were binned using $2^{\circ} \times 2^{\circ}$ bins, and the PoT analysis was applied to both wind speed and wave height for the altimeter data and wind speed for the radiometer data. Vinoth and Young (2011) attempted a similar analysis with the result showing extremely noisy distributions. They concluded that the distributions of $H_{s}^{100}$ showed promise but that the $U_{10}^{100}$ estimates were unusable.

Figure 4 shows color-filled contour plots of $U_{10}^{100}$ (Fig. 4a) and $H_{s}^{100}$ (Fig. 4b) for the altimeter (PoT). The contours have been drawn on the $2^{\circ} \times 2^{\circ}$ grid without further smoothing. In comparison to the findings of Vinoth and Young (2011), the results show a far smoother spatial distribution. The contours of $U_{10}^{100}$ show much greater zonal structure than $H_{s}^{100}$. This is consistent with mean monthly climatology (Young 1994, 1999; Young and Donelan 2018) and is caused by the dispersive nature of waves. Once generated, waves propagate across oceanic basins as swell (Young et al. 2013), ensuring a smoother distribution of $H_{s}$ than $U_{10}$. This is also the case for the extreme values, as shown in Fig. 4.

Figure 4a shows the maxima of $U_{10}^{100}$ of approximately $38 \mathrm{~m} \mathrm{~s}^{-1}$ occur in the North Atlantic and North Pacific. 

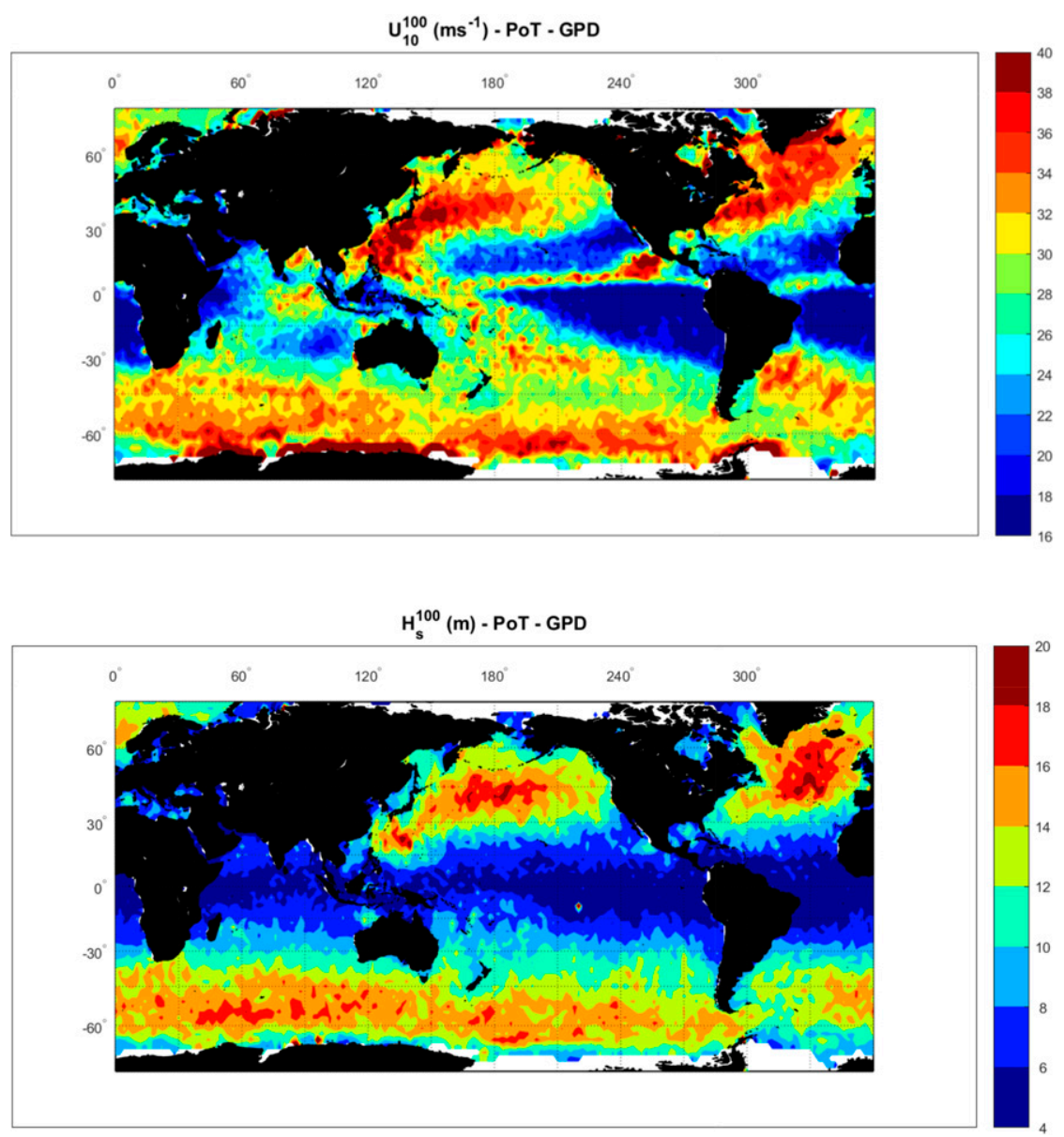

FIG. 4. Global values of (top) $U_{10}^{100}\left(\mathrm{~m} \mathrm{~s}^{-1}\right)$ and (bottom) $H_{s}^{100}(\mathrm{~m})$ obtained with a PoT analysis and a GPD distribution. Data obtained from altimeter missions.

Although the Southern Ocean is consistently windy year-round and monthly means in winter are comparable to the Northern Hemisphere (Young 1999; Young and Donelan 2018), the extremes are not as great. The maximum values of $U_{10}^{100}$ in the Southern Ocean are approximately $34 \mathrm{~m} \mathrm{~s}^{-1}$. This maximum tends to occur south of the Indian Ocean (between Australia and South Africa). The maxima in the North Atlantic and North Pacific tend to be displaced toward the western boundaries of these basins. The reason for this can be seen by examining Fig. 5, which shows the storm tracks of tropical cyclones (and tropical low pressure systems) over the period 1984-2014, obtained from the IBTrACS data archive (Knapp et al. 2010). For clarity, only every second storm track is shown in Fig. 5.

Figure 5 shows that North Atlantic and Pacific tropical storms track east to west across the tropics of each ocean basin, respectively, before turning north along the western boundary of each basin. Because of the small spatial scale of tropical cyclones and the relatively large distance between altimeter tracks, it is likely that these systems are undersampled in the present analysis. As such systems move north, they tend to increase in size, making it more likely that they are observed by the altimeter. This is clear in the region of the western North Atlantic, where extreme winds are predicted (Fig. 4a) north of $30^{\circ} \mathrm{N}$, but there is no clear indication of tropical cyclones moving across the tropical regions of the Atlantic (east to west). In contrast, extreme winds along the western boundary of the Pacific are predicted as far south as $10^{\circ} \mathrm{N}$. There is then a clear path of intense winds shown across the Pacific equatorial regions. North Pacific tropical cyclones (typhoons) tend to be larger in spatial extent than North Atlantic tropical cyclones (hurricanes; Knaff et al. 2014). They are also more frequent, as shown in Fig. 5, making them less affected by undersampling in the altimeter dataset. This explains why the east-west tropical track is clear in the western Pacific $\left(10^{\circ} \mathrm{N}\right)$ but not the western Atlantic. 


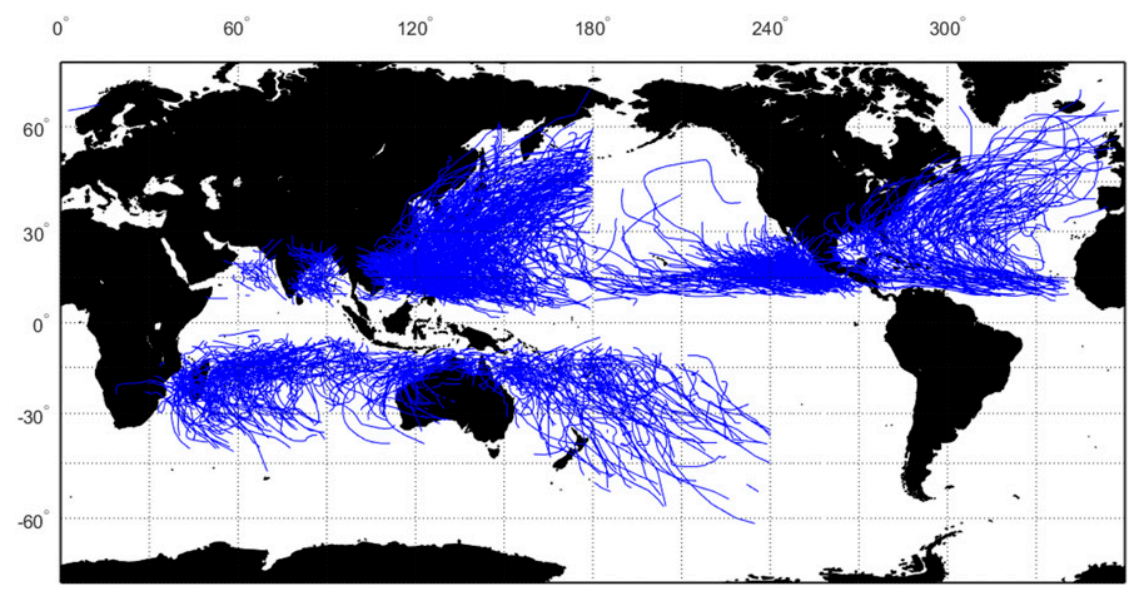

FIG. 5. Storm tracks of tropical cyclones (and tropical low pressure systems) over the period 1984-2014, obtained from the IBTrACS data archive (Knapp et al. 2010). For clarity, only every second track is plotted.

A number of other storm track features can also be seen in the values of $U_{10}^{100}$ in Fig. 4a. The region of high occurrence of tropical cyclones near the central American Pacific coast is reflected in a "hot spot" of extreme wind of approximately $38 \mathrm{~m} \mathrm{~s}^{-1}$ in that region. There is a region of reduced $U_{10}^{100}$ in the central Indian Ocean. Figure 5 shows that this corresponds to a region almost devoid of tropical cyclones between the western Australian and eastern African basins. Less clearly, there is also a band of slightly elevated $U_{10}^{100}$ from northeast of New Zealand to east of New Guinea. Again, this corresponds to the track regions for South Pacific storms. A further hot spot of elevated $U_{10}^{100}$ can be seen in the Bay of Bengal, another region of high occurrence of tropical cyclones.

The eastern side of the South Atlantic (off Africa) shows relatively low values of $U_{10}^{100}$ with the exception of a band of slightly increased values along the equator between South America and North Africa. It is probable that this is the signature of storm activity in the intertropical convergence zone (ITCZ). A triangular region of low $U_{10}^{100}$ bounded by the equator west of South America is also clear in Fig. 4a.

Many of the same features described above are also apparent in model calculations of $U_{10}^{100}$ (Breivik et al. 2014; Meucci et al. 2018). Both the location and magnitudes of the maximum values in the North Atlantic and Pacific Oceans are comparable to Fig. 4a. Also, the relatively low values in the triangular region west of South America and across the Atlantic west of Africa are found in both the model and altimeter data in Fig. 4a. However, features that we have attributed to small-scale tropical cyclone activity are not clear in the model results. This includes tropical cyclone activity across the
Pacific north of the equator, or in the Pacific Ocean east of Australia or the low-extremes area in the central Indian Ocean. It should be pointed out that neither the model results nor the altimeter dataset are optimal for investigating tropical cyclone extremes. The spatial resolution of the models (e.g., of order $100 \mathrm{~km}$ ) means that tropical cyclone winds will not be resolved. In contrast, the altimeter will measure tropical cyclone winds (Young 1993), provided there is a ground track close to the tropical cyclone. However, as noted above, these storms will be undersampled. Therefore, the differences between $U_{10}^{100}$ from model data and altimeter are as one would expect.

Figure 4b shows color-filled contours of $H_{s}^{100}$ calculated using the PoT method and altimeter data. As noted previously, there is much less small-scale variability than for $U_{10}^{100}$ (Fig. 4a). The largest values of $H_{s}^{100}$ are once again in the North Atlantic and North Pacific, with values of approximately $18 \mathrm{~m}$. Again, the regions with the largest extreme waves are displaced toward the western boundaries of these basins, but not to the same extent as the wind $U_{10}^{100}$ (Fig. $4 \mathrm{a}$ ). Similar to the extreme winds, the largest values of $H_{s}^{100}$ in the Southern Hemisphere are found south of the Indian Ocean between Australia and South Africa, with values of approximately $16 \mathrm{~m}$. Values of $H_{s}^{100}$ gradually decrease from these maximum regions in each hemisphere toward the equator. In the equatorial regions, $H_{s}^{100}$ reaches only approximately $4 \mathrm{~m}$. These results are much smoother (spatially) than the PoT results of Vinoth and Young (2011) and agree well with model results (Breivik et al. 2014; Meucci et al. 2018) both in magnitude and spatial distribution.

It is believed that Fig. 4 represents the first plausible published estimates of $U_{10}^{100}$ and $H_{s}^{100}$ obtained from 

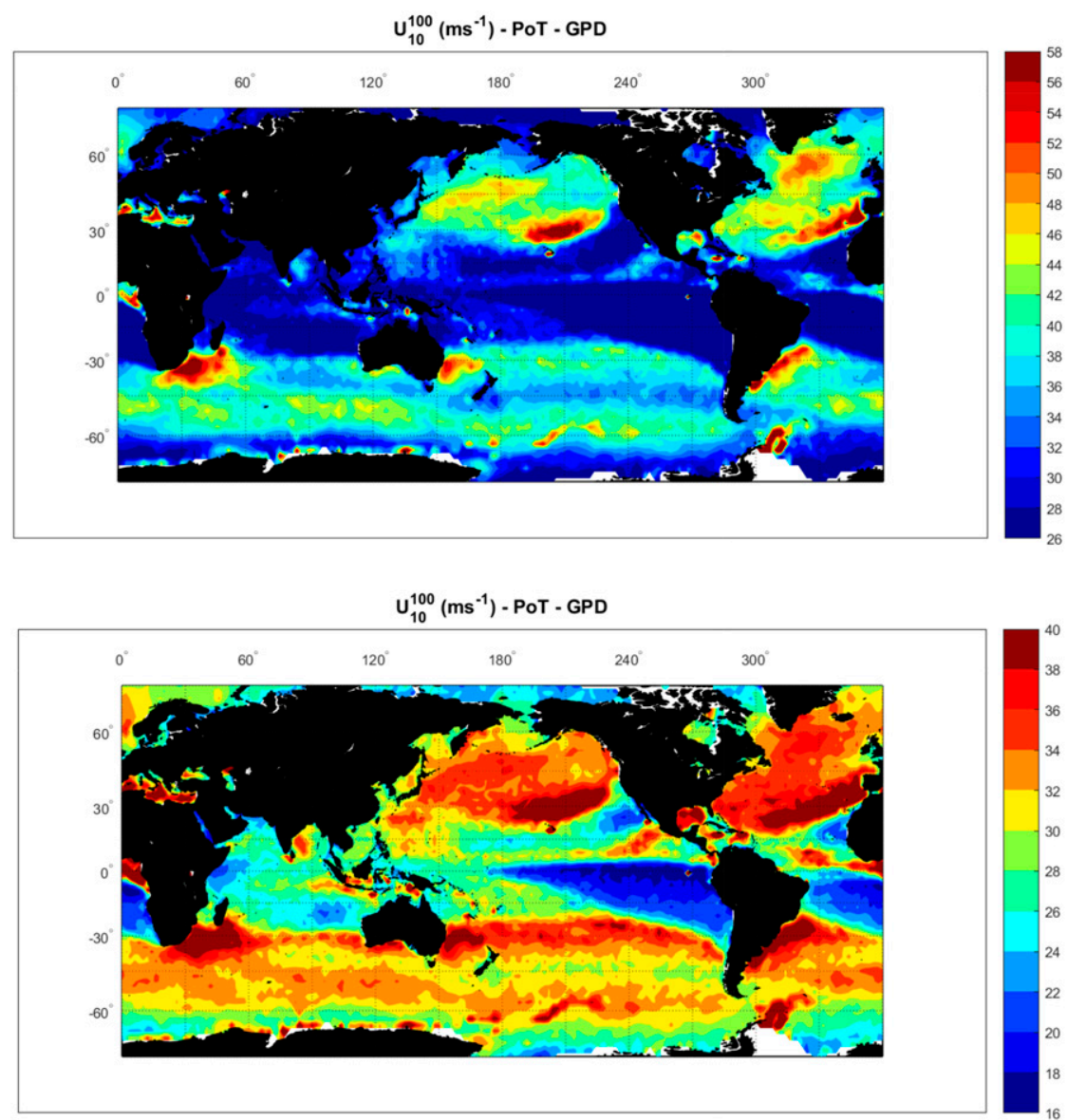

FIG. 6. Global values of $U_{10}^{100}\left(\mathrm{~m} \mathrm{~s}^{-1}\right)$ obtained with a PoT analysis and a GPD distribution. Data obtained from radiometer missions. (top) No high wind speed correction applied to the data. (bottom) The high wind speed correction [(7)] applied to the data.

altimeter using a PoT analysis. These results do suffer from the undersampling of small-scale meteorological systems (e.g., tropical cyclones, storms) but are probably less affected than low-resolution model data.

\section{b. Radiometer PoT analysis}

Because of the much higher data rates (30 times more data) the radiometer has the potential to address the undersampling issues noted above for altimeter $U_{10}^{100}$ estimates with the PoT analysis. However, the radiometer also has features that are undesirable at high wind speeds. First, as noted in section 4, collocation between anemometer and radiometer measurements shows that the radiometers overestimate wind speed above approximately $20 \mathrm{~m} \mathrm{~s}^{-1}$. We have attempted to address this issue by the high wind speed correction in (7). In addition, however, the radiometer cannot measure in heavy rain. Examination of numerous cases of radiometer passes over tropical cyclones in the present dataset indicated that in almost all cases, a data "hole" exists around the center of the storm with no useable data and, importantly, the high wind speeds being missed by the radiometer. The same characteristic is clear in many high-latitude storms with a data gap near the center of the storm.

Figure 6 shows color-filled contours of $U_{10}^{100}$ obtained from the radiometer and the PoT analysis. Figure 6a shows the result without the high wind speed correction $[(7)]$ and Fig. 6b with the inclusion of the correction. In comparing the radiometer $U_{10}^{100}$ result with the altimeter values, it should be noted that the color scale in Fig. 6a (radiometer) is $26-58 \mathrm{~m} \mathrm{~s}^{-1}$ compared to Fig. 4a (altimeter) of $16-40 \mathrm{~m} \mathrm{~s}^{-1}$. That is, the radiometer without the high wind speed correction gives values of $U_{10}^{100}$ much higher than the altimeter, previous model results (Breivik et al. 2014; Meucci et al. 2018), and the buoy data of Table 1. With the high wind speed correction (Fig. 6b), the results are now of comparable magnitude to the altimeter (Figs. 4a and 6b have the same color scale). Also, Fig. $6 \mathrm{~b}$ shows many of the same spatial 


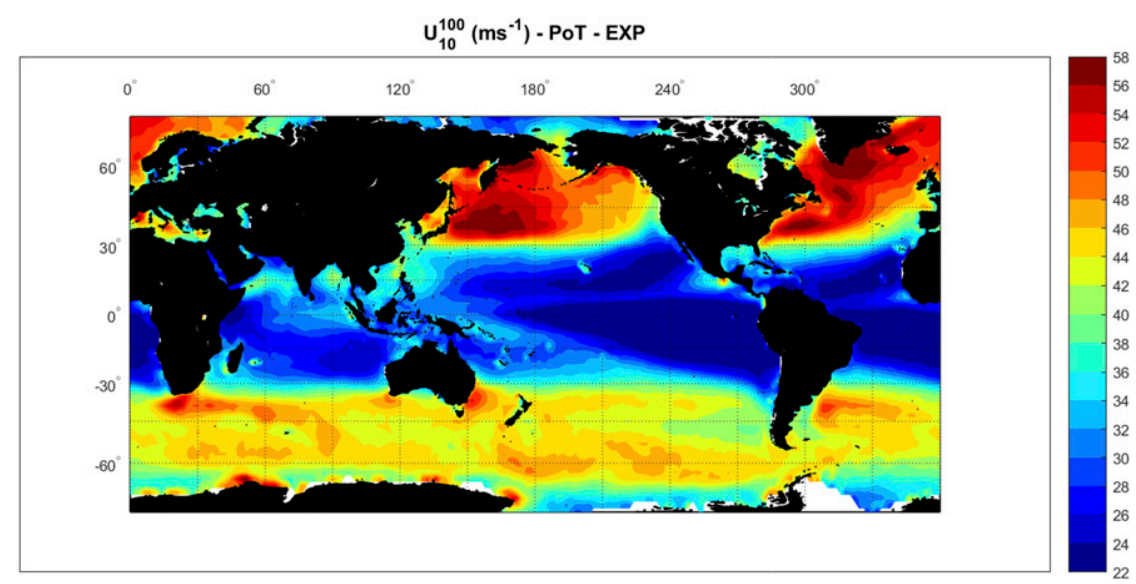

FIG. 7. Global values of $U_{10}^{100}\left(\mathrm{~m} \mathrm{~s}^{-1}\right)$ obtained with a PoT analysis and an EXP distribution. Data obtained from radiometer missions. The high wind speed correction [(7)] applied to the data.

features as Fig. 4a-highest values in the North Atlantic and Pacific, low-wind triangular region in the Pacific west of South America, tropical cyclone belt across the Pacific (but less distinct), ITCZ band across the equatorial Atlantic (but less distinct), and the low wind speed region in the Indian Ocean.

There are, however, a number of features in Fig. 6b that differ from the altimeter results. The largest values of $U_{10}^{100}$ do not occur in the storm belts at about $45^{\circ} \mathrm{N}$, rather they occur in distinct separate belts at around $30^{\circ} \mathrm{N}$. Similarly, a belt of high values of $U_{10}^{100}$ exists across the Southern Hemisphere at approximately $30^{\circ} \mathrm{S}$, rather than farther south in the Southern Ocean as in the altimeter data. Examination of the PDFs of the radiometer showed that at the higher latitudes, $\pm 45^{\circ}$, the tail was abruptly truncated (i.e., no high values). This resulted in a GPD [(5)] fit to the data with a negative shape parameter $k$. This places an upper bound on $U_{10}^{100}$. In contrast, at lower latitudes $k$ remained positive, producing no upper bound and the larger values of $U_{10}^{100}$ produced at $\pm 30^{\circ}$. We speculate that the lack of high wind speed data at $\pm 45^{\circ}$ is caused by the extreme winds not being sensed by the radiometer because of high rain rates. As the spatial distributions in Fig. 6b (or Fig. 6a) are not plausible, we searched for an alternative fit to the radiometer PDFs.

In an attempt to address the issues raised above, an exponential (EXP) distribution was used with the PoT analysis rather than a GPD. The EXP distribution is a special case of the GPD [(5)] with $k=0$. This produces an unbounded distribution but without the variability caused by having $k$ determined by the fit to the data (which is problematic in the tail of the radiometer PDF). The resulting values of $U_{10}^{100}$ are shown in Fig. 7. As in
Fig. 6b, the high wind speed correction [(7)] has been used but with the EXP distribution.

Although the use of the EXP has produced results that vary spatially in a smooth manner, the spatial distributions are quite different from the altimeter GPD (and previously published results; Vinoth and Young 2011; Breivik et al. 2014). Although the high wind speed correction [(7)] was used for the data in Fig. 7, the magnitude of the values of $U_{10}^{100}$ are much greater than Fig. 4a (altimeter, GPD)—scale $22-58 \mathrm{~m} \mathrm{~s}^{-1}$. As a result, we conclude that the EXP distribution produces unsatisfactory results.

The results of Figs. 6 and 7 indicate that, despite the greater sampling density provided by the radiometer, its inability to provide data during rain events introduces an unacceptable fair-weather bias for extreme-value applications.

\section{c. IDM analysis}

As noted earlier, all previous studies of extreme-value estimates from satellite data (altimeter) have opted for an IDM analysis. This is despite the many shortcomings of the approach outlined in section 2a (value of decorrelation scale $D$, independent and identically distributed data). As the present analysis provides, for the first time, stable estimates of both $U_{10}^{100}$ and $H_{s}^{100}$ from a PoT analysis, these can be used as a basis to assess the usefulness of an IDM analysis.

Figures $8 \mathrm{a}$ and $8 \mathrm{~b}$ show $U_{10}^{100}$ and $H_{s}^{100}$, respectively, for an IDM analysis of altimeter data. Figure 9 shows $U_{10}^{100}$ for an IDM analysis of radiometer data. As noted in Table 1, the decorrelation scales $D$ were chosen so as to give results of comparable magnitudes to the altimeter and buoy PoT results $\left(U_{10}^{100}, D=500 \mathrm{~h} ; H_{s}^{100}, D=30 \mathrm{~h}\right)$. 

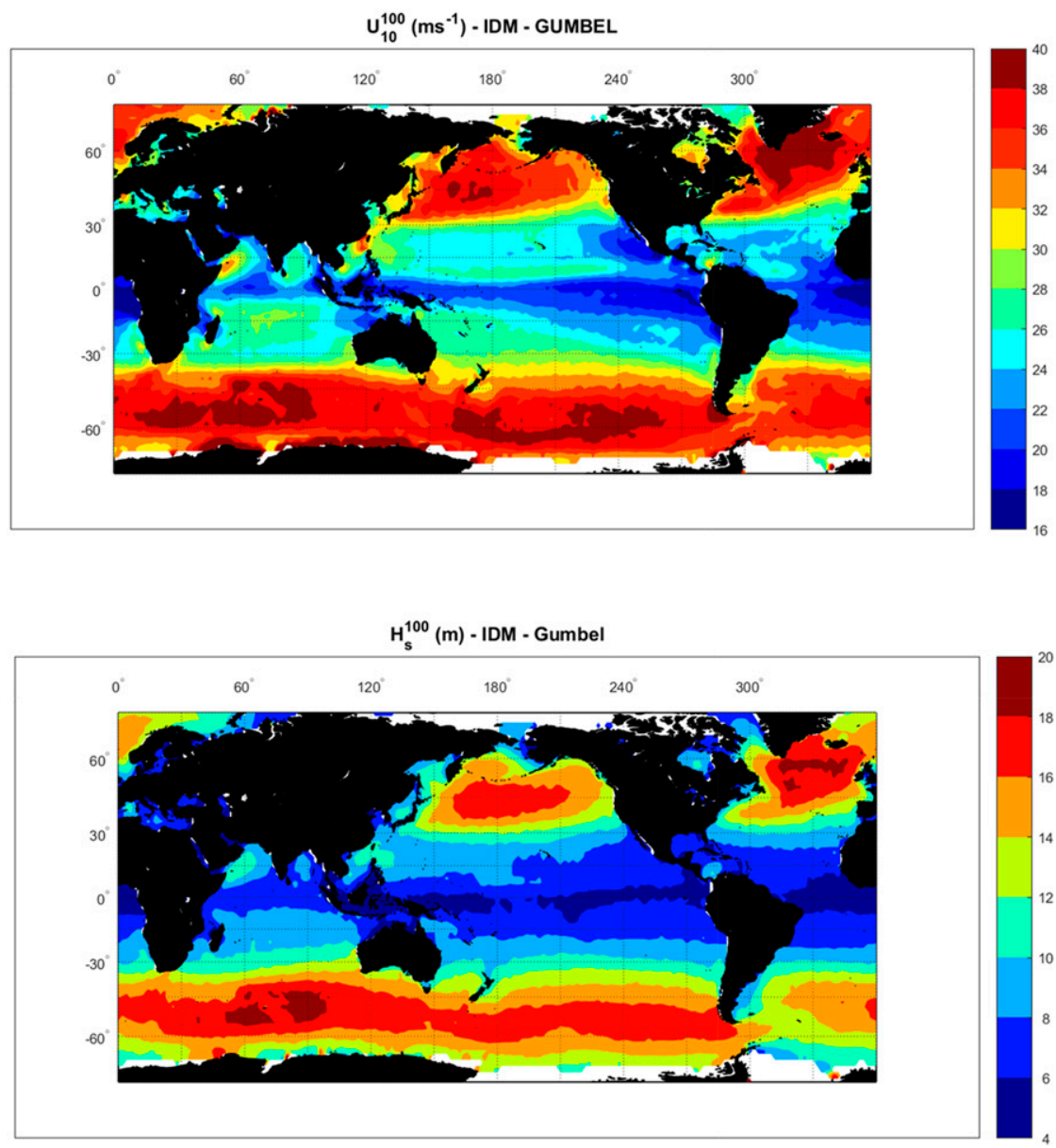

FIG. 8. Global values of (top) $U_{10}^{100}\left(\mathrm{~m} \mathrm{~s}^{-1}\right)$ and (bottom) $H_{s}^{100}(\mathrm{~m})$ obtained with an IDM analysis and a Gumbel distribution. Data obtained from altimeter missions.

As expected, the results show smooth spatial distributions. Also, the values of $U_{10}^{100}$ produced by both altimeter and radiometer are very similar. This is in stark contrast to the results for the PoT analysis. Although this may seem a positive feature of the IDM, this occurs because the IDM fit to the PDF is controlled by the body of the PDF rather than the tail. The altimeters and radiometers produce mean monthly wind speeds in good agreement (Young and Donelan 2018). Therefore, they will produce IDM fits to the data that are also similar. The fact that the tails of the respective distributions are quite different has little impact on the resulting values of $U_{10}^{100}$. The spatial distributions of $U_{10}^{100}$ are also very similar to the mean monthly distributions. For instance, the maximum values in each hemisphere are of similar magnitude (not the case for the PoT) and the distributions in the North Atlantic and Pacific are more centrally located, rather than being in the storm belts. Although there is some suggestion of a tropical cyclone belt across the Pacific, this is much less distinct than for the PoT analysis and all other tropical cyclone signatures are absent in the IDM analysis. Another interesting difference is that the PoT analysis did not show a local maximum in the area of the Horn of Africa, as a result of the Somali/Oman coastal low-level jet (CLLJ; Ranjha et al. 2015). In contrast, the IDM shows a distinct local maximum (see below and Fig. 11).

The values of $H_{s}^{100}$ largely follow the same spatial distributions as $U_{10}^{100}$ (cf. Fig. 8a and Fig. 8b). This again occurs because the spatial distributions of mean wind speeds and wave heights are similar.

Figures 10 and 11 show the PDFs for both wind speed and wave height, together with both IDM and PoT fits to the data. Figure 10 shows results from a location in the Pacific Ocean tropical cyclone belt $\left(6^{\circ} \mathrm{N}, 214^{\circ} \mathrm{E}\right.$; Figs. $10 \mathrm{a}-\mathrm{d}, U_{10}$; Fig. $\left.10 \mathrm{e}-\mathrm{h}, H_{s}\right)$, and Fig. 11 shows results from a location off the Horn of Africa $\left(14^{\circ} \mathrm{N}\right.$, $60^{\circ} \mathrm{E}$; Figs. $11 \mathrm{a}-\mathrm{d}, U_{10}$; Figs. $\left.11 \mathrm{e}-\mathrm{h}, H_{s}\right)$. These are two locations where the IDM and PoT analyses give very different results. Figures 10a-d show that the PDF of 


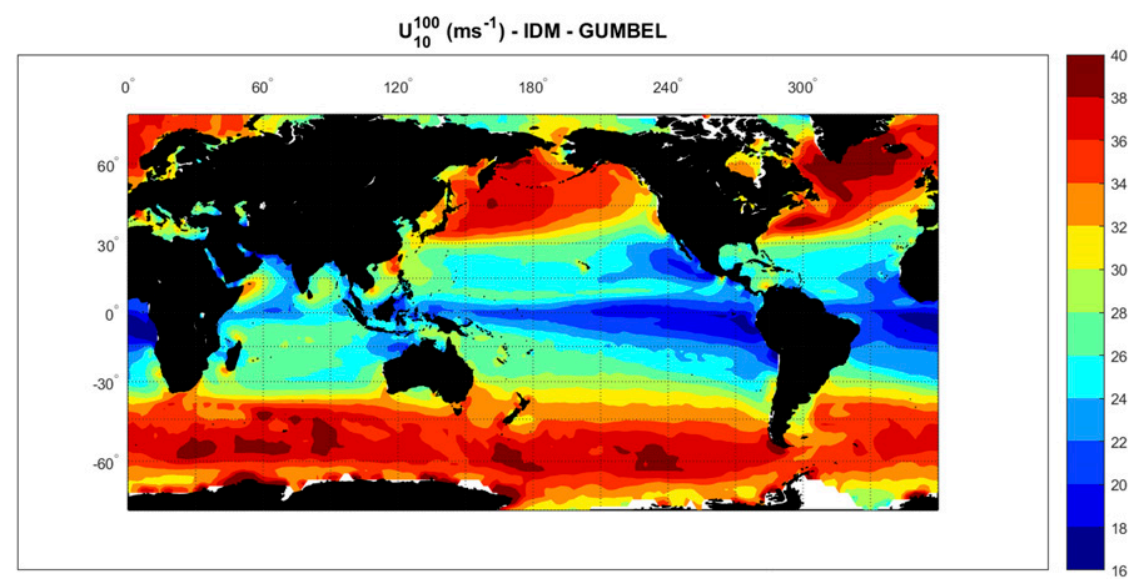

FIG. 9. Global values of $U_{10}^{100}\left(\mathrm{~m} \mathrm{~s}^{-1}\right)$ obtained with an IDM analysis and a Gumbel distribution. Data obtained from radiometer missions. The high wind speed correction [(7)] applied to the data.

$U_{10}$ has a relatively low wind speed peak at $U_{10} \approx$ $8 \mathrm{~m} \mathrm{~s}^{-1}$, however, an extended high wind speed tail caused by the presence of tropical cyclones. The IDM fits poorly to the tail and underestimates $U_{10}^{100}$. In contrast, the PoT with a GPD fit to the tail region more accurately approximates the data. The differences for $H_{s}$ are not as great because the wave field is more uniformly distributed (no local maximum band). As such, the PDF is reasonably well modeled by both IDM and PoT, and the values of $H_{s}^{100}$ from the two approaches do not differ greatly.

The PDFs for the Horn of Africa (Fig. 11) are clearly affected by the strong winds of the Somali/Oman CLLJ. The PDFs (both wind speed and wave height) are clearly bimodal and there are clearly two populations of wind speed and wave height. It is also clear that the high wind speed peak (Somali/Oman CLLJ) has a very sharp dropoff with increasing $U_{10}$. This indicates that, although the winds in the jet are high, there are few really extreme events. Both approaches struggle to model the tail of the PDF. However, the IDM greatly overestimates the tail of the distribution, resulting in a localized peak in $U_{10}^{100}$, which is not supported by the shape of the PDF, as well as not predicted by the PoT analysis. A similar situation exists for $H_{s}$, with the IDM again overestimating the tail of the PDF.

The comparisons between the PoT and IDM analyses above clearly show the limitations of the IDM approach. Although this approach has found favor when working with short datasets, the results shown here clearly indicate its significant theoretical and practical shortcomings. As long-duration satellite and model reanalysis datasets are now available, there seems little justification for its continued use.

\section{d. Changing wind and wave climates}

The above analysis assumes that the time series considered are stationary. That is, there is no change in the mean conditions over the approximately 30 -yr measurement period. In addition, applying such extremevalue analysis to determine probable extremes also assumes that mean conditions will not change in the future. There is evidence to suggest that there have been changes in both wind and wave mean climate over this period (Young et al. 2011). In addition, there is also some evidence that extreme conditions have also changed over this period (Young et al. 2011, 2012). Further, model studies (Hemer et al. 2013) indicate that wave climate may also change in the future. At present, there is still a significant level of uncertainty in these trend estimations. The present estimates of both historical and future trends are relatively small (mean $H_{s}$ trends of approximately $0.5 \mathrm{~cm} \mathrm{yr}^{-1}$; mean $U_{10}$ approximately $2 \mathrm{~cm} \mathrm{~s}^{-1} \mathrm{yr}^{-1}$ ). To date, no reliable assessment of the potential impact on extreme conditions exists.

\section{Conclusions}

The present analysis outlines the application of extreme-value analysis to long-duration (30 year) global altimeter and radiometer datasets. In contrast to previous extreme-value analyses of satellite data, the dataset is sufficiently long to enable a PoT analysis to be undertaken. When applied to altimeter data for $U_{10}$ and $H_{s}$, this PoT analysis produces values consistent with buoy validation data and previous numerical model reanalysis datasets. The spatial distributions produced are also consistent with the model reanalysis data. However, 

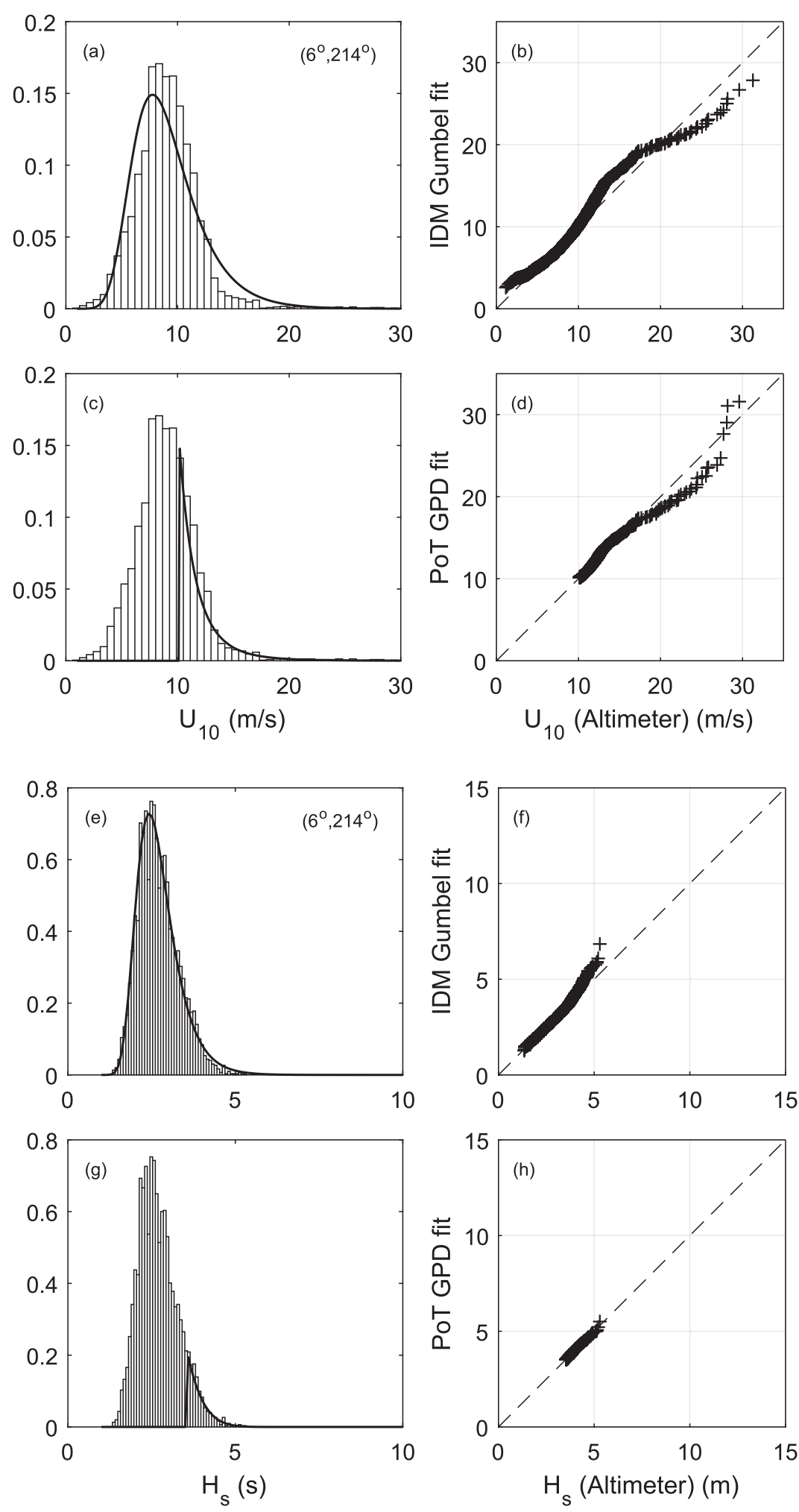

FIG. 10. The altimeter (left) PDF and (right) QQ plot at a $2^{\circ} \times 2^{\circ}$ square centered on $6^{\circ} \mathrm{N}, 214^{\circ} \mathrm{E}$ (Pacific tropical cyclone belt) for wind speed $U_{10}$. (a),(b) The IDM fit to the PDF and (c),(d) the PoT fit to the PDF. (e)-(h) As in (a)-(d), but for wave height $H_{s}$. 

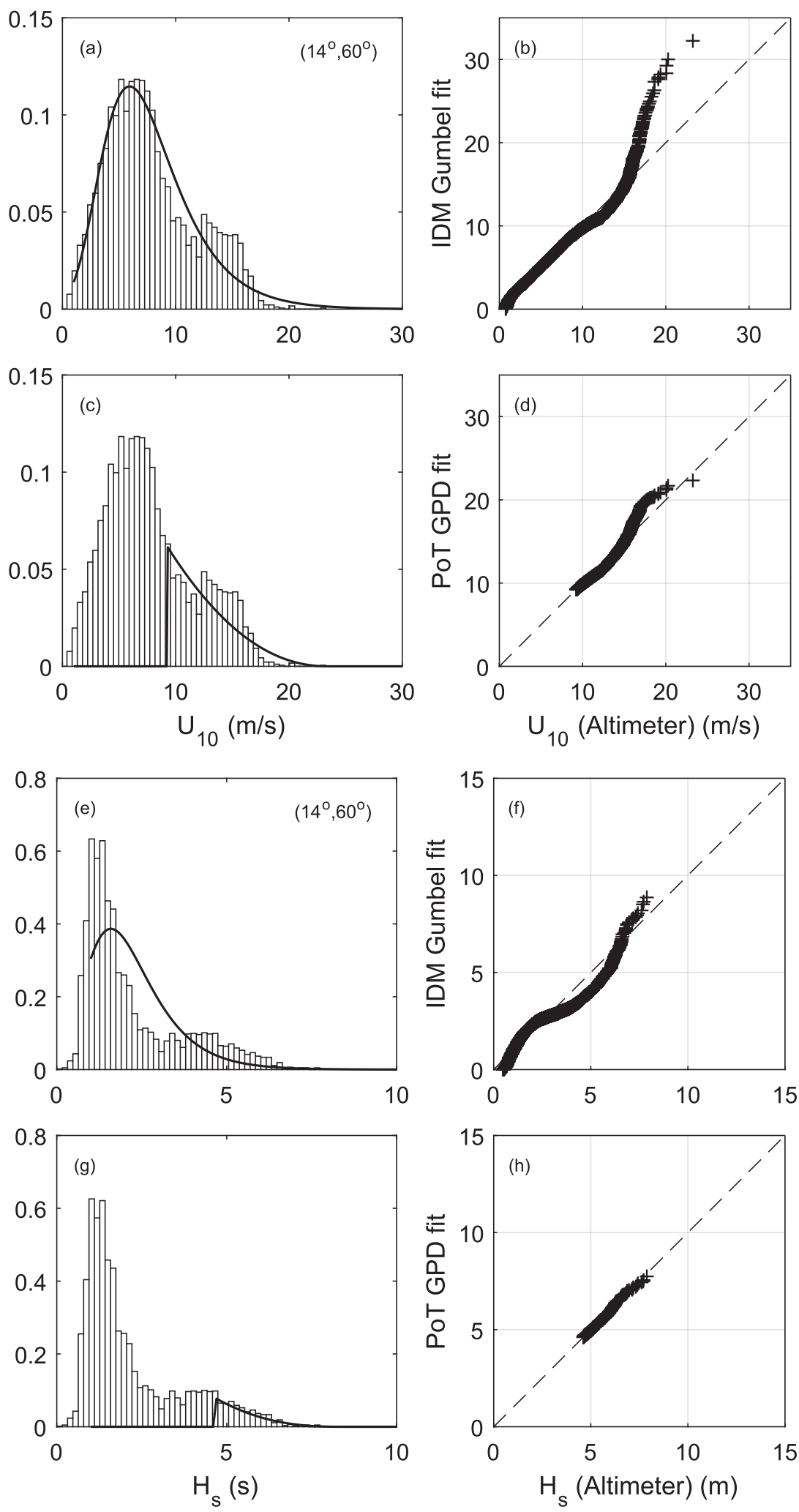

FIG. 11. As in Fig. 10, but for a $2^{\circ} \times 2^{\circ}$ square centered on $14^{\circ} \mathrm{N}, 60^{\circ} \mathrm{E}$ (Horn of Africa). 
the altimeter data show much greater finescale structure $\left(U_{10}^{100}\right)$, which is consistent with known tropical cyclone activity (not generally resolved by reanalysis model datasets). Although the altimeter must undersample tropical cyclones to some extent, the present results are encouraging and, as the number of altimeter missions continues to increase and the data record expands, the quality of the extreme-value projections will improve further.

The greater data density provided by radiometer measurements offers the potential to address altimeter undersampling issues. However, issues associated with the radiometer inability to measure wind speed in heavy rain events appears to create an unacceptable "fair weather" bias at extreme wind speeds. This renders the radiometer data of $U_{10}$ largely unusable for PoT EVA.

Because of the relatively short duration of altimeter data, previous EVA studies have all used IDM analyses for EVA. The extended dataset presented here can now be successfully processed using the more theoretically sound PoT approach. The present analysis shows that the IDM yields quite biased estimates of extreme values and their spatial distributions. As the PoT approach can now be successfully applied to the available longer satellite datasets, there seems little reason for IDM analyses to be used in the future.

Acknowledgments. IRY gratefully acknowledges the support of the Australian Research Council through Grants DP130100215 and DP160100738. This support has been invaluable in completing this extensive study. The raw datasets used in the study were supplied by Globwave (altimeter and buoy) and Remote Sensing Systems (RSS; radiometer/scatterometer). Without these public domain archives, the study would have been extremely difficult. ØB gratefully acknowledges support from the Research Council of Norway through the ExWaMar project (Grant Number 256466) and the European Research Area for Climate Services through the WINDSURFER project.

\section{REFERENCES}

Aarnes, O. J., Ø. Breivik, and M. Reistad, 2012: Wave extremes in the northeast Atlantic. J. Climate, 25, 1529-1543, https://doi.org/ 10.1175/JCLI-D-11-00132.1.

__ S. Abdalla, J.-R. Bidlot, and Ø. Breivik, 2015: Marine wind and wave height trends at different ERA-Interim forecast ranges. J. Climate, 28, 819-837, https://doi.org/10.1175/ JCLI-D-14-00470.1.

Abdalla, S., 2007: Ku-band radar altimeter surface wind speed algorithm. Proc. Envisat Symp. 2007, Montreux, Switzerland, European Centre for Medium-Range Weather Forecasts, 463250, https://earth.esa.int/envisatsymposium/proceedings/ sessions/3E4/463250sa.pdf.
Alves, J. H. G. M., and I. R. Young, 2003: On estimating extreme wave heights using combined Geosat, Topex/Poseidon and ERS-1 altimeter data. Appl. Ocean Res., 25, 167-186, https://doi.org/ 10.1016/j.apor.2004.01.002.

Anderson, C. W., D. J. T. Carter, and P. D. Cotton, 2001: Wave climate variability and impact on offshore structure design extremes. Shell International Rep., 88 pp.

Bender, L. C., III, N. Guinasso Jr., J. N. Walpert, and S. D. Howden, 2010: A comparison of methods for determining significant wave heights-Applied to a 3-m discus buoy during Hurricane Katrina. J. Atmos. Oceanic Technol., 27, 1012-1028, https://doi.org/10.1175/2010JTECHO724.1.

Breivik, Ø., O. J. Aarnes, J.-R. Bidlot, A. Carrasco, and Ø. Saetra, 2013: Wave extremes in the northeast Atlantic from ensemble forecasts. J. Climate, 26, 7525-7540, https://doi.org/10.1175/ JCLI-D-12-00738.1.

,-- , S. Abdalla, J.-R. Bidlot, and P. A. E. M. Janssen, 2014: Wind and wave extremes over the world oceans from very large ensembles. Geophys. Res. Lett., 41, 5122-5131, https:// doi.org/10.1002/2014GL060997.

Caires, S., and A. Sterl, 2005: 100-year return value estimates for ocean wind speed and significant wave height from the ERA40 data. J. Climate, 18, 1032-1048, https://doi.org/10.1175/ JCLI-3312.1.

Castillo, E., 1988: Extreme Value Theory in Engineering. Academic Press, $389 \mathrm{pp}$

Challenor, P. G., W. Wimmer, and I. Ashton, 2005: Climate change and extreme wave heights in the North Atlantic. Proc. 2004 Envisat and ERS Symp., Salzburg, Austria, European Space Agency, SP-572.

Chen, G., S.-W. Bi, and R. Ezraty, 2004: Global structure of extreme wind and wave climate derived from TOPEX altimeter data. Int. J. Remote Sens., 25, 1005-1018, https://doi.org/ 10.1080/01431160310001598980.

Coles, S., 2001: An Introduction to Statistical Modelling of Extreme Value Theory. Springer, $209 \mathrm{pp}$.

Cooper, C. K., and G. Z. Forristall, 1997: The use of satellite data to estimate extreme wave climate. J. Atmos. Oceanic Technol., 14, 254-266, https://doi.org/10.1175/1520-0426(1997)014<0254: TUOSAD $>2.0 . \mathrm{CO} ; 2$.

Dee, D. P., and Coauthors, 2011: The ERA-Interim reanalysis: Configuration and performance of the data assimilation system. Quart. J. Roy. Meteor. Soc., 137, 553-597, https://doi.org/10.1002/qj.828.

Evans, D., C. L. Conrad, and F. M. Paul, 2003: Handbook of automated data quality control checks and procedures of the National Data Buoy Center. NOAA National Data Buoy Center Tech. Doc. 03-02, 44 pp.

Ferreira, J. A., and C. G. Soares, 1998: An application of the peaks over threshold method to predict extremes of significant wave height. J. Offshore Mech. Arct. Eng., 120,165-176, https://doi.org/ 10.1115/1.2829537.

Goda, Y., 1988: On the methodology of selecting design wave height. Proc. 21st Int. Conf. on Coastal Eng., Malaga, Spain, American Society of Civil Engineers, 899-913.

1992: Uncertainty in design parameter from the viewpoint of statistical variability. J. Offshore Mech. Arct. Eng., 114, 76-82, https://doi.org/10.1115/1.2919962.

Hasselmann, S., and Coauthors, 1988: The WAM Model-A third generation ocean wave prediction model. J. Phys. Oceanogr., 18, 1775-1810, https://doi.org/10.1175/1520-0485(1988)018<1775: TWMTGO $>2.0 . \mathrm{CO} ; 2$.

Hemer, M. A., Y. Fan, N. Mori, A. Semedo, and X. L. Wang, 2013: Projected changes in wave climate from a multi-model 
ensemble. Nat. Climate Change, 3, 471-476, https://doi.org/ 10.1038/nclimate1791.

Howden, S., D. Gilhousen, N. Guinasso, J. Walpert, M. Sturgeon, and L. Bender, 2008: Hurricane Katrina winds measured by a buoy-mounted sonic anemometer. J. Atmos. Oceanic Technol., 25, 607-616, https://doi.org/10.1175/2007JTECHO518.1.

Jensen, R. E., V. R. Swail, R. H. Bouchard, R. E. Riley, T. J. Hesser, M. Blaseckie, and C. MacIsaac, 2015: Field Laboratory for Ocean Sea State Investigation and Experimentation: FLOSSIE: Intra-measurement evaluation of $6 \mathrm{~N}$ wave buoy systems. 14th Int. Workshop on Wave Hindcasting and Forecasting and Fifth Coastal Hazard Symp., Key West, FL, WMO/IOC JCOMM, A1, http://www.waveworkshop.org/14thWaves/Papers/ WW14\%20FLOSSIE\%20Jensen\%20et\%20al.pdf.

Knaff, J. A., S. P. Longmore, and D. A. Molenar, 2014: An objective satellite-based tropical cyclone size climatology. J. Climate, 27, 455-476, https://doi.org/10.1175/JCLI-D-1300096.1; Corrigendum, 28, 8648-8651, https://doi.org/10.1175/ JCLI-D-15-0610.1.

Knapp, K. R., M. C. Kruk, D. H. Levinson, H. J. Diamond, and C. J. Neumann, 2010: The International Best Track Archive for Climate Stewardship (IBTrACS): Unifying tropical cyclone data. Bull. Amer. Meteor. Soc., 91, 363-376, https://doi.org/ 10.1175/2009BAMS2755.1.

Large, W. G., J. Morzel, and G. B. Crawford, 1995: Accounting for surface wave distortion of the marine wind profile in low-level ocean storms wind measurements. J. Phys. Oceanogr., 25, 2959-2971, https://doi.org/10.1175/1520-0485(1995)025<2959: AFSWDO $>2.0 . \mathrm{CO} ; 2$.

Lopatoukhin, L. J., V. A. Rozhkov, V. E. Ryabinin, V. R. Swail, A. V. Boukhanovsky, and A. B. Degtyarev, 2000: Estimation of extreme wind wave heights. WMO/TD-1041, 84 pp., https://www. wmo.int/pages/prog/amp/mmop/documents/JCOMM-TR/J-TR9-ExtWaveHeight/JCOMM-TR-9-Extr-Wave-Height-Full.pdf.

Meucci, A., I. R. Young, and Ø. Breivik, 2018: Wind and wave extremes from atmosphere and wave model ensembles. J. Climate, 31, 8819-8843, https://doi.org/10.1175/JCLI-D-18-0217.1.

Ochi, M. K., 1992: New approach in estimating the severest sea state from statistical data. Proc. Coastal Eng. Conf., New York, NY, American Society of Civil Engineers, 512-523.

Ranjha, R., and Coauthors, 2015: Structure and variability of the Oman coastal low-level jet. Tellus, 67A, 25285, https://doi.org/ 10.3402/tellusa.v67.25285.

Sterl, A., and S. Caires, 2005: Climatology, variability and extrema of ocean waves: The web-based KNMI/ERA-40 wave atlas. Int. J. Climatol., 25, 963-977, https://doi.org/10.1002/joc.1175.

Stopa, J. E., and K. F. Cheung, 2014: Intercomparison of wind and wave data from the ECMWF Reanalysis Interim and the NCEP Climate Forecast System Reanalysis. Ocean Modell., 75, 65-83, https://doi.org/10.1016/j.ocemod.2013.12.006.

Taylor, P. K., and M. J. Yelland, 2001: Comments on "On the effect of ocean waves on the kinetic energy balance and consequences for the inertial dissipation technique.' J. Phys. Oceanogr., 31, 2532-2536, https://doi.org/10.1175/1520-0485(2001)031<2532: COOTEO $>2.0 . \mathrm{CO} ; 2$.

Teng, C. C., 1998: Long-term and extreme waves in the Gulf of Mexico. Proc. Conf. on Ocean Wave Kinematics and Loads on Structures, Houston, TX, ASME, 342-349.

Tucker, M. J., 1991: Waves in Ocean Engineering. Ellis Horwood, $431 \mathrm{pp}$.

Uppala, S. M., and Coauthors, 2005: The ERA-40 Re-Analysis. Quart. J. Roy. Meteor. Soc., 131, 2961-3012, https://doi.org/ 10.1256/qj.04.176.

Van Gelder, P. H. A. J. M., and J. K. Vrijling, 1999: On the distribution function of the maximum wave height in front of reflecting structures. Proc. Coastal Structures Conf., Santander, Spain, American Society of Civil Engineers, 37-46.

Vinoth, J., and I. R. Young, 2011: Global estimates of extreme wind speed and wave height. J. Climate, 24, 1647-1665, https:// doi.org/10.1175/2010JCLI3680.1.

Wimmer, W., P. Challenor, and C. Retzler, 2006: Extreme wave heights in the North Atlantic from altimeter data. Renewable Energy, 31, 241-248, https://doi.org/10.1016/j.renene.2005.08.019.

Young, I. R., 1993: An estimate of the Geosat altimeter wind speed algorithm at high wind speeds. J. Geophys. Res., 98, 20275 20285 , https://doi.org/10.1029/93JC02117.

_ 1994: Global ocean wave statistics obtained from satellite observations. Appl. Ocean Res., 16, 235-248, https://doi.org/ 10.1016/0141-1187(94)90023-X.

_ 1999: Seasonal variability of the global ocean wind and wave climate. Int. J. Climatol., 19, 931-950, https://doi.org/10.1002 (SICI)1097-0088(199907)19:9<931::AID-JOC412>3.0.CO;2-O.

_ , and M. A. Donelan, 2018: On the determination of global ocean wind and wave climate from satellite observations. Remote Sens. Environ., 215, 228-241, https://doi.org/10.1016/ j.rse.2018.06.006.

— S. Zieger, and A. V. Babanin, 2011: Global trends in wind speed and wave height. Science, 332, 451-455, https://doi.org/ 10.1126/science.1197219.

— J. Vinoth, S. Zieger, and A. V. Babanin, 2012: Investigation of trends in extreme value wave height and wind speed. J. Geophys. Res., 117, C00J06, https://doi.org/10.1029/ 2011JC007753.

- A. V. Babanin, and S. Zieger, 2013: The decay rate of ocean swell observed by altimeter. J. Phys. Oceanogr., 43, 2322-2333, https://doi.org/10.1175/JPO-D-13-083.1.

— E. Sanina, and A.V. Babanin, 2017: Calibration and crossvalidation of a global wind and wave database of altimeter, radiometer and scatterometer measurements. J. Atmos. Oceanic Technol., 34, 1285-1306, https://doi.org/10.1175/ JTECH-D-16-0145.1.

Zeng, L., and R. A. Brown, 1998: Scatterometer observations at high wind speeds. J. Appl. Meteor., 37, 1412-1420, https://doi.org/ 10.1175/1520-0450(1998)037<1412:SOAHWS >2.0.CO;2. 